requests again suggests that casualty officers had difficulty in determining on clinical grounds alone whether there was a fracture or other abnormality.

Thirdly, a further third of all requests were made to reassure the patient. If the casualty officers were thus using radiographs as an addition to verbal reassurance this would appear to be a disturbing practice which, on the face of it, should be discouraged. But there are cases when radiographs play a valid part in reassurance. For example, a manual worker who has injured the tuft of his terminal phalanx will be reassured that a fracture has not been shown on the $x$-ray film, even though its demonstration would not have affected clinical management. The casualty consultant, however, made only half as many requests for patient reassurance as did the juniors. This is to be expected in that an experienced general surgeon will be more confident in both his clinical expertise and in his ability to reassure patients without the aid of radiographs. Some requests made for patient reassurance by the juniors may in fact have been an expression of clinical doubt about whether an injury was or was not present. Nevertheless, even if the number of $x$-ray examinations requested by the consultant for patient reassurance is taken as being the more accurate, this remains surprisingly high at $18^{\circ}$ of all requests.

The yield of positive radiographic findings was low among patients whose radiographs had been requested to reassure them or for medicolegal reasons. Nevertheless, it is disturbing that $6^{\circ}, \mathrm{o}$ of cases referred for reassurance and $8^{\circ}$ o referred solely for medicolegal reasons by the junior casualty officers had clinically significant $x$-ray abnormalities.

Our results suggest that junior casualty officers in particular have difficulty in determining by clinical examination alone whether a significant abnormality, usually a fracture, is or is not present. The current level of $x$-ray referral, often regarded as being excessive, ${ }^{2} 4$ may well be appropriate and commensurate with the level of clinical knowledge, confidence, and experience of the casualty officers. Nevertheless, there are areas in which the number of films per examination can be reduced ${ }^{5}$ (see accompanying paper below) and others where clinical guidelines on the likelihood of a significant radiographic finding have been suggested. ${ }^{6-8}$ Until such measures are accepted and put into practice and until clinical experience and acumen are improved, an appreciable reduction in the number of $x$-ray referrals in accident and emergency departments is unlikely.

We thank Dr John Williams and the clerical staff in the $x$-ray department at St George's Hospital, SW1; Dr Frank Vajda for his help with the manuscript; and Christine Chamberlain for typing.

\section{References}

${ }^{1}$ Raison, J C A, Proceedings of the Royal Society of Medicine, 1976, 69, 755.

2 Golberg, B, British Medical fournal, 1977, 2, 1274.

3 Addison, P, British Medical fournal, 1971, 2, 278.

4 Evans, K T, British fournal of Radiology, 1977, 50, 299.

5 de Lacey, G J, Proceedings of the Royal Society of Medicine, 1976, 69, 758.

${ }^{6}$ Garfield, J S, Lancet, 1960, 2, 1167.

7 de Lacey, G J, et al, British fournal of Radiology, 1977, 50, 412.

${ }^{8}$ Boulis, Z F, Dick, R, and Barnes, N R, British fournal of Radiology, 1978, $51,851$.

(Accepted 4 April 1979)

\title{
Rationalising requests for x-ray examination of acute ankle injuries
}

\author{
GERALD DE LACEY, SHIRLEY BRADBROOKE
}

British Medical fournal, 1979, 1, 1597-1598

If the simple maxim of "No swelling adjacent to a malleolus, no radiographs" were applied radiography of twisted ankles could be reduced by as much as twothirds. Moreover, if this maxim included the rider "and

\section{Summary and conclusions}

Radiographs of injured ankles represent about 1 in 50 of all radiological examinations. The notes and radiographs of 100 patients with ankle injuries were reviewed, and the films of a further 93 patients who had ankle fractures treated by immobilisation were also scrutinised to assess the presence or absence of soft tissue swelling over the malleoli. Any accompanying radiographs of the foot requested at the same time were also studied. In 65 of the 100 cases of ankle injury there was no soft tissue swelling, and none of the patients had a major fracture, while 92 of the 93 patients with a major fracture had soft tissue swelling at the level of the malleoli. In 32 of the 100 cases of ankle injury foot radiographs had also been requested, but only three foot injuries were found.

\footnotetext{
Department of Diagnostic Radiology, St George's Hospital, London SW1

GERALD DE LACEY, MB, FRCR, consultant radiologist (present address: Department of Diagnostic Radiology, Northwick Park Hospital and Clinical Research Centre, Harrow, Middlesex)

SHIRLEY BRADBROOKE, MB, FRCR, senior registrar
} no routine foot films" the total casualty radiographic work load could be reduced by $8 \%$.

\section{Introduction}

Ankle radiographs represented $10 \%$ of examinations requested from the casualty department at St George's Hospital, London SW1 in 1975. In 1960 Garfield $^{1}$ suggested that if there is no soft tissue swelling after an ankle injury then a radiograph is not clinically useful. We wanted to determine the number of patients attending the casualty department who underwent ankle radiography without having soft tissue swelling adjacent to either malleolus. We also assessed the number of patients with ankle injuries who also had foot films requested.

\section{Patients and methods}

The $x$-ray films, casualty cards, and, when applicable, the notes of 100 consecutive patients who attended the accident department at $\mathrm{St}$ George's Hospital during 1975 and were referred for radiography of the ankle were reviewed retrospectively. All injuries were sustained while falling downstairs, walking, or running. No distinction was made 
between the type of movement that occurred at the time of injuryexternal rotation, inversion, or eversion-nor was the time interval between injury and $x$-ray examination recorded.

The history and results of clinical examination were noted, initial $x$-ray films examined, the presence of swelling adjacent to either malleolus assessed radiographically, and the clinical management documented. Similar details were also recorded in a second group of 93 patients who had major ankle fractures put into plaster. The patients in this group were those seen at two hospitals (St George's Hospital, London SW1 and London SW 17) from 1970 to 1976 whose notes and films were available. The ages of the patients with acute ankle injuries ranged from 8 years to 73 years, two being under 16 . The ages of the 93 patients with ankle fractures ranged from 11 years to 96 years, four being under 16 .

\section{Results}

Sixty-five of the 100 consecutive casualty attenders referred for radiographs of their ankle had no radiographic evidence of swelling adjacent to either malleolus (see table). Five of these patients did

Soft tissue appearance on the radiograph at the level of the malleoli

\begin{tabular}{|c|c|c|c|c|}
\hline \multirow{2}{*}{$\begin{array}{c}\text { Soft } \\
\text { tissue } \\
\text { swelling }\end{array}$} & \multicolumn{3}{|c|}{$\begin{array}{l}100 \text { consecutive casualty attenders } \\
\text { referred for ankle radiographs }\end{array}$} & \multirow{2}{*}{$\begin{array}{l}93 \text { patients } \\
\text { with major } \\
\text { ankle fractures } \\
\text { put in plaster }\end{array}$} \\
\hline & $\begin{array}{c}\text { No } \\
\text { fracture }\end{array}$ & $\begin{array}{l}\text { Minor fracture: } \\
\text { strapping only }\end{array}$ & $\begin{array}{c}\text { Major } \\
\text { fracture }\end{array}$ & \\
\hline $\begin{array}{c}>10 \mathrm{~mm} \\
5-10 \mathrm{~mm} \\
\text { None }\end{array}$ & $\begin{array}{r}5 \\
20 \\
60\end{array}$ & $\begin{array}{l}4 \\
6 \\
5\end{array}$ & $\begin{array}{l}0 \\
0 \\
0\end{array}$ & $\begin{array}{c}85 \\
7 \\
1^{*}\end{array}$ \\
\hline
\end{tabular}

* 11-year-cld girl who fell from a height of $8 \mathrm{ft}$.

have fractures, but all the fractures were minor and treated with strapping only. There were no major fractures requiring immobilisation in this group.

In the group of 93 patients with fractures treated by immobilisation the initial radiographs showed soft tissue swelling over at least one malleolus in 92 cases (see table). The swelling was usually adjacent to the malleolus which was fractured, but in a few cases it was present only next to the intact malleolus. The one patient who did not have soft tissue swelling was 11 years old, had fallen from a height of $8 \mathrm{ft}$, and had sustained an oblique fracture of the fibula with displacement of the lower tibial epiphysis.

In most of the 100 cases it was possible to determine from the notes whether there was injury, pain, tenderness, or swelling of the foot and thus whether additional foot films might be useful. In the few cases where this information was inadequate we presumed that there had been a foot injury. Feet as well as ankle films had been requested in 32 of the 100 patients, and in 15 of these cases there were good clinical notes but no suggestion of an injury to the foot. Altogether, three abnormalities were shown on the 32 films of the feet. One was.a fracture of the fifth metatarsal, and the clinical record indicated that this and not the ankle was the site of injury. In another case there was a fracture of the middle phalanx of the little toe, and no clinical reason for requesting the ankle films could be detected. The third patient had a small flake detached from the cuboid.

\section{Discussion}

About $10 \%$ of $x$-ray examinations performed in casualty departments, or one in every 50 of all radiographs performed in a general hospital, are of an ankle. Nevertheless, our findings show that major fractures are uncommon. In a study of 111 patients with injuries to the ankle, Garfield ${ }^{1}$ concluded that the absence of clinical soft tissue swelling indicates strongly that no important bony or ligamentous damage is present and that radiographs will not be helpful in management.

Swelling anterior or inferior to the malleoli cannot be accurately assessed from radiography, but assessment is accurate at the level of the malleoli on the anteroposterior film because of the small amount of overlying soft tissue and because the two malleoli may be compared for asymmetry. Sixty-five out of 100 patients with no major fracture of the ankle had no swelling adjacent to the malleolus, while 92 out of 93 patients who did have major fractures also had soft tissue swelling around the malleolus. The one patient with a major fracture and no swelling was an 11-year-old. This suggests that soft tissue swelling may be absent in some young patients with major fractures. Soft tissue swelling does not always occur immediately after an ankle injury, and the time between injury and $x$-ray examination was not recorded in any of our patients. Nevertheless, all the adults with fractures requiring immobilisation had soft tissue swelling on their initial radiographs, and the swelling is unlikely to have occurred during the interval between the casualty officer signing the $x$-ray request and the film being exposed.

It has been suggested that some casualty officers request foot films when an injury is solely limited to the ankle, ${ }^{2}$ and our results confirmed this impression. The requests for films of the foot as well as of the ankle seemed to have been made not because the foot was injured but because the combination of films is often regarded as a routine examination.

Since ankle films represent the most common $x$-ray examination requested as a result of trauma, a sensible economy would be obtained by following the simple principle that a radiograph will not be helpful in an adult who presents with an acute ankle injury and has no swelling specifically adjacent to either malleolus. Sixty-five per cent of the patients referred for $x$-ray whom we studied did not have swelling adjacent to either malleolus, and none had a major fracture. Thus if this principle had been followed in this hospital in 1975 it would have reduced the number of ankle radiographs in adults from just over 1000 to about 350 . Moreover, $34 \%$ of the patients referred for ankle radiographs also had foot films requested, yet $47 \%$ of these had no evidence of an injury to the foot. If the clinical guideline about the absence of swelling adjacent to a malleolus had been extended to include "and no routine foot films," then as many as 800 of the 10000 accident and emergency $x$-ray examinations need not have been performed.

We thank Anthony Barker and Robin Bendall for their constructive criticism and Christine Chamberlain for typing.

\section{References \\ 1 Garfield, J S, Lancet, 1960, 2, 1167. \\ 2 Golberg, B, British Medical fournal, 1977, 2, 1274.}

(Accepted 4 April 1979)

ONE HUNDRED YEARS AGO At the recent meeting of the Society of German Surgeons, Herr Urlichs read a report of some researches, made by $\mathrm{Dr}$ Bergmann of Würzburg, on pigmentbacteria in dressings. The most frequently occurring of these organisms are the blue ones. They are easily transferred from one wound to another, but are quite harmless. In addition to the colour, they are characterised by a clayey sweetish odour, which may be present even when there is no colouring. When colourless bacteria, having this characteristic odour, were transferred to a healthy granulating ulcer of the leg, a blue colouring of the dressings was produced in twenty-four hours. The result of adding blue pus to Pasteur's fluid was always the production of colourless and odourless bacteria; but, when these colourless bacteria were transferred to the compresses used in dressing, the blue colour is restored. When yellow pigment-bacteria was cultivated in Pasteur's fluid, and dressings were inoculated with the colourless result, blue pus was always produced. The same result was obtained by treating red pigment-bacteria in the same way. Dr Bergmann concludes, from these researches, that there is a close interchangeability of the pigment-forming bacteria with one another and with the colourless bacteria of Pasteur's fluid. In the discussion, Dr von Langenbeck remarked that blue pus was often met with when camphorated spirit was used as a dressing. (British Medical fournal, 1879.) 